\title{
Monte Carlo Simulations for Mine Detection
}

\author{
A. Toor, A.A. Marchetti
}

March 14, 2000

U.S. Department of Energy

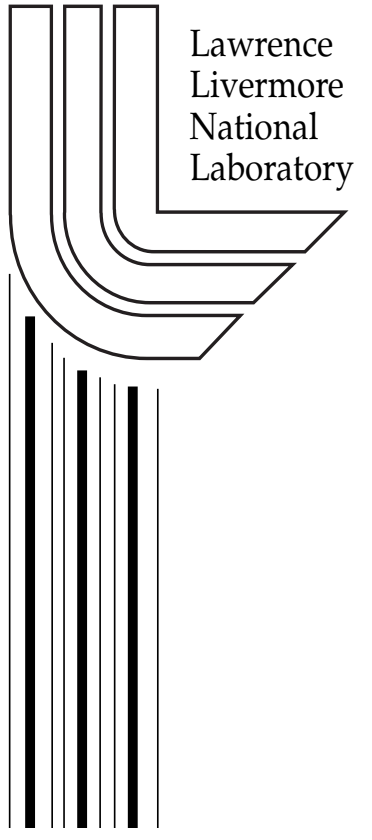




\section{DISCLAIMER}

This document was prepared as an account of work sponsored by an agency of the United States Government. Neither the United States Government nor the University of California nor any of their employees, makes any warranty, express or implied, or assumes any legal liability or responsibility for the accuracy, completeness, or usefulness of any information, apparatus, product, or process disclosed, or represents that its use would not infringe privately owned rights. Reference herein to any specific commercial product, process, or service by trade name, trademark, manufacturer, or otherwise, does not necessarily constitute or imply its endorsement, recommendation, or favoring by the United States Government or the University of California. The views and opinions of authors expressed herein do not necessarily state or reflect those of the United States Government or the University of California, and shall not be used for advertising or product endorsement purposes.

Work performed under the auspices of the U. S. Department of Energy by the University of California Lawrence Livermore National Laboratory under Contract W-7405-Eng-48.

This report has been reproduced directly from the best available copy.

Available to DOE and DOE contractors from the

Office of Scientific and Technical Information

P.O. Box 62, Oak Ridge, TN 37831

Prices available from (423) 576-8401

http://apollo.osti.gov/bridge/

Available to the public from the National Technical Information Service

U.S. Department of Commerce 5285 Port Royal Rd., Springfield, VA 22161 http://www.ntis.gov/

OR Lawrence Livermore National Laboratory Technical Information Department's Digital Library http://www.llnl.gov/tid/Library.html 


\section{Monte Carlo Simulations for Mine Detection \\ 99-FS-009 Final Report \\ UCRL-ID-138119}

A. Toor, A.A. Marchetti

\section{$\underline{\text { Introduction }}$}

During January, 1998, collaboration between LLNL, UCI and Exdet, Ltd. arranged for the testing and evaluation of a Russian developed antitank mine detection system at the Buried Objects Detection Facility (BODF) located at the Nevada Test Site. BODF is a secured 30-acre facility with approximately 300 live antitank mines that were buried in 1993 and 1994. The burial depths range from a few $\mathrm{cm}$ to $15 \mathrm{~cm}$ and the various metaland plastic-case antitank mines each contain 6-12 kg of high explosive. Contractors who have tested their mine detection equipment at BODF include: SAIC, SRI, ERIM, MIT/Lincoln Laboratory and Loral Defense Systems. In addition LLNL researchers have used BODF to test antitank mine detection systems based on: dual-band infrared imaging, hyper-spectral imaging, synthetic aperture impulse radar and micro-impulse radar. In a blind test the Russian operated system obtained the highest score of any technology tested to date at BODF. The system is based on combining information from two separate sensors; one to detect anomalous concentrations of hydrogen and the other to detect if such anomalies also have the correct nitrogen to carbon ratio for high explosives. The detection sensitivity is set by the geometry and type of neutron moderator and filters surrounding the neutron source and detectors. Detection of hydrogen anomalies is a rapid process based on neutron scattering. The handheld instrument on the end of a wand could scan a large area at a rate of 4-5 square meters per minute. Once the hydrogen anomalies were located a second sensor was used to measure the thermal neutron excited gamma-ray spectrum at each hydrogen anomaly to determine whether that location in addition contained high concentrations of nitrogen. The second process was slower, taking up to 5 minutes for each location. The information from both sensors were then examined by the operator and a declaration was made as to whether or not the anomaly was a buried antitank mine.

Although the system worked extremely well on all classes of anti-tank mines, the Russian hardware components were inferior to those that are commercially available in the United States, i.e. the $\mathrm{NaI}(\mathrm{Tl})$ crystals had significantly higher background levels and poorer resolution than their U.S. counterparts, the electronics appeared to be decades old and the photomultiplier tubes were noisy and lacked gain stabilization circuitry. During the evaluation of this technology, the question that came to mind was: could state-of-the-art sensors and electronics and improved software algorithms lead to a neutron based system that could reliably detect much smaller buried mines; namely antipersonnel mines containing 30-40 grams of high explosive?

Our goal in this study was to conduct Monte Carlo simulations to gain better understanding of both phases of the mine detection system and to develop an 
understanding for the system's overall capabilities and limitations. In addition, we examined possible extensions of this technology to see whether or not state-of-the-art improvements could lead to a reliable anti-personnel mine detection system.

\section{$\underline{\text { Antitank Mine Detection System }}$}

The first phase of detection used a neutron source to irradiate the soil and the backscattered neutron flux $\left(\mathrm{n}, \mathrm{n}^{\prime}\right)$ was measured. It is well known that the neutron scattering and moderating abilities for the low-z elements in high explosives $(\mathrm{H}, \mathrm{C}, \mathrm{O}$, and $\mathrm{N}$ ) are several times higher than for the heavier elements found in most dry soils ( $\mathrm{Si}$, $\mathrm{Fe}, \mathrm{Ca}$, etc.) (1). The backscattered neutron flux at the soil surface can therefore be several times higher when neutron source is over a shallow buried mine compared to the backscattered flux from the soil only. The main advantage of neutron backscattering (its high sensitivity to changes in $\mathrm{H}$ concentrations) can unfortunately lead to a high rate of false alarms from sub-surface concentrations of moisture and buried items such as pieces of plastic or wood. Measuring backscattered neutrons proved to be a rapid way to identify hydrogen anomalies, but there were too many false alarms for this technique to be useful by itself as mine detection system.

The geometry of the hand held unit containing the neutron source and neutron detectors is shown in Fig. 1. An isotropic ${ }^{252} \mathrm{Cf}$ fission neutron source $\left(1.2 \times 10^{7} \mathrm{n} / \mathrm{sec}\right)$ was mounted inside a cylindrical aluminum casing having an internal radius of $1 \mathrm{~cm}$, a wall thickness of $0.5 \mathrm{~cm}$, and a height of $1.5 \mathrm{~cm}$. The aluminum cylinder was inserted in a cylindrical hole in a $10 \mathrm{~cm} \times 10 \mathrm{~cm} \times 5 \mathrm{~cm}$ block of polyethylene. The sides and top of the polyethylene block were covered with an unknown thickness of a "neutron reflector" backed by an unknown thickness of cadmium. The sides and back were treated in our simulations as perfect neutron absorbers. The polyethylene block was mounted on an 24 $\mathrm{cm} \times 24 \mathrm{~cm}$ base consisting of a 1-mm thick sheet of copper on top of a 2-mm thick sheet of aluminum. Figure 1 also shows 1-mm thick "heavy metal filters" below the polyethylene block to reduce the flux of thermal neutrons from the source region and "counter screens" to improve the signal to background ratio. Since we were unable to obtain any information on these features they were left out in our simulations. A moderated ${ }^{3} \mathrm{He}$ neutron detector, 2-cm diameter, $20-\mathrm{cm}$ long, and laterally displaced by 9 $\mathrm{cm}$ was mounted symmetrically on each side of the neutron source. A shaped, composite shield to provide lateral confinement of the neutron flux was placed between the neutron source and ${ }^{3} \mathrm{He}$ detectors.

The second phase of detection used a neutron source to irradiate the soil and the secondary gamma rays resulting from thermal neutron $(n, \gamma)$ reactions were measured. The gamma-rays energy spectrum provides a unique signature of for buried explosives $(\mathrm{H}$ - 2.2 MeV, C-4.0 MeV, 0-6.0 MeV, and N-10.8 MeV). A NaI(Tl) crystal and photomultiplier tube were used to measure the gamma spectrum. In the experiments at BODF the same ${ }^{252} \mathrm{Cf}$ neutron source was used for both the first and second phase of detection, although optimally the neutron spectra for $\left(n, n^{\prime}\right)$ and $(n, \gamma)$ interactions would be tailored quite differently (2). The geometry for the gamma sensor is shown in Fig. 2. 


\section{Monte Carlo Simulations}

We conducted Monte Carlo simulations for both phases of the Russian detection system. We used three Monte Carlo codes: COG(3) and TART(4) developed at LLNL and MCNP(5) developed at LANL. COG is a high-resolution code for the Monte Carlo simulation of coupled neutron, gamma, and electron transport in arbitrary 3-D geometry. COG solves the Boltzmann equation for the transport of neutrons and photons, and links to the EGS (6) electron transport code kernel for the transport of electrons. COG has many variance reduction techniques, which enable it to solve difficult deep-penetration shielding problems. TART is a coupled neutron-photon, 3-Dimensional, combinatorial geometry, time dependent Monte Carlo transport code. Neutron cross sections can either be taken from the LLNL ENDL library or a newer 650-group treatment covering the energy range $10^{-4} \mathrm{eV}$ up to $1 \mathrm{GeV}$. We ran a test case with all three codes to identify possible errors in our input decks and to look for possible systematics due to differing physics packages in the codes. For this particular problem all three codes gave essentially identical results and the majority of our subsequent runs were made with MCNP. Typical examples of the source decks for the MCNP runs corresponding to "mine plus soil" and "soil only" are listed in Appendix A and Appendix B.

Because the ( $\left.\mathrm{n}, \mathrm{n}^{\prime}\right)$ reaction rate is especially sensitive to low $\mathrm{z}$ elements, our simulations used the measured soil composition at BODF (7) and included moisture content that was measured in-situ while the tests were being conducted. Typical values of the volumetric water content $\left(\mathrm{cm}^{3}\right.$ of $\mathrm{H}_{2} \mathrm{O}$ per $\mathrm{cm}^{3}$ of soil) vs. depth are shown in Fig. 3 for both vegetated and bare soils.

Using the published fission neutron spectrum for ${ }^{252} \mathrm{Cf}(8)$, we calculated the detection sensitivity for a prototypical antitank landmine buried at depths ranging from $2.5-10$ $\mathrm{cm}$. Table 1 lists the results from a MCNP calculation using 4 neutron energy groups between $0.001 \mathrm{eV}$ and $10 \mathrm{eV}$ and twenty million neutron particle histories. Columns three and four compare the detected neutrons backscattered from the soil with the detected neutrons backscattered from the soil plus $5 \mathrm{~kg}$ cylinder of TNT $(20 \mathrm{~cm}$ diameter, $10 \mathrm{~cm}$ high) buried $2.5 \mathrm{~cm}$ below the surface. The signal to background ratio exceeded 2 throughout the thermal region of the spectrum and the fraction of neutrons scattered from the TNT that reached the detector was $\sim 0.1 \%$. Therefore, our simulations based on the geometry in Fig. 1 predict the backscattered signal would be easily detected. Detailed comparisons of our simulations with the field data were limited by the amount of quantitative information we were able to obtain from the Russians on their system. For instance we were told the high-z case behind the polyethylene block contained experimentally optimized layers of filters and moderators to increase the neutron albedo and provide maximum flux at a burial depth of $10-\mathrm{cm}$. The Russian scientists were reluctant to divulge information regarding specific dimensions and materials for any of the filters and moderators that were not accessible to visual inspection. In addition we were unable to obtain detailed quantitative information on the Russian electronics (i.e. the pulse forming circuits, the neutron energy threshold and the integration time constants). Nevertheless, our simulations are in qualitative agreement with the field data in that they 
predicted statistically significant signals for every declaration in the field test where the hydrogen concentration was in fact due to a buried mine.

Table 1: Monte Carlo simulation (20 million histories) of backscattered neutrons from 5 $\mathrm{kg}$ TNT buried at $2.5 \mathrm{~cm}$

\begin{tabular}{|c|c|c|c|c|}
\hline $\begin{array}{c}\mathrm{E}_{\min } \\
(\mathrm{MeV})\end{array}$ & $\begin{array}{c}\mathrm{E}_{\max } \\
(\mathrm{MeV})\end{array}$ & $\begin{array}{c}\text { Soil } \\
\text { (neutrons) }\end{array}$ & $\begin{array}{c}\text { Soil+TNT } \\
\text { (neutrons) }\end{array}$ & (Soil+TNT)/Soil \\
\hline $1.0 \times 10^{-9}$ & $1.0 \times 10^{-8}$ & 287 & 745 & 2.6 \\
\hline $1.0 \times 10^{-8}$ & $1.0 \times 10^{-7}$ & 6118 & 14274 & 2.3 \\
\hline $1.0 \times 10^{-7}$ & $1.0 \times 10^{-6}$ & 4019 & 9410 & 2.3 \\
\hline $1.0 \times 10^{-6}$ & $1.0 \times 10^{-5}$ & 4146 & 9374 & 2.3 \\
\hline
\end{tabular}

The second phase or nitrogen determination phase of detection was simulated with MCNP using the neutron source and detector geometry shown in Fig. 2. The antitank mine was defined as a 5-kg cylinder of TNT (20-cm diameter, 10-cm high) buried at distances of 2.5 to $15 \mathrm{~cm}$ below the soil surface. The neutron source was again an isotropic ${ }^{252} \mathrm{Cf}$ fission neutron source. A cylindrical $\mathrm{NaI}(\mathrm{Tl})$ detector, 11.2-cm diameter, $6 \mathrm{~cm}$ in height, was radially displaced $15 \mathrm{~cm}$ from the shielded neutron source. The detector and neutron source were positioned $5 \mathrm{~cm}$ above the surface of the soil. Figure 4 compares the gamma flux incident on the detector for the soil only [Fig. 4(a)] and the soil plus TNT [Fig 4(b)]. The photon peak at $10.8 \mathrm{MeV}$, corresponding to the ${ }^{14} \mathrm{~N}(\mathrm{n}, \gamma)$ reaction, is clearly seen when the TNT is present. Although the resulting signal would be weak, the natural occurring background and background arising from neutron capture with other environmentally occurring elements in this region of the spectrum is extremely low. With the detector geometry shown in Fig. 2 and a detection efficiency of $1 \times 10^{-2}$, a statistically significant $(3 \sigma)$ signal would be obtained in about 3 minutes. This is in agreement with the field data where typically 3-5 minute time integrations were necessary to make the declaration of whether or not the hydrogen anomaly located in the first phase was a buried mine.

The second phase detection system was claimed to incorporate electronic software that combined information from the gamma peaks associated with the delayed gamma-ray reactions in carbon $(h v=4.9 \mathrm{MeV})$, silicon $(\mathrm{h} v=8.5 \mathrm{MeV})$, and nitrogen $(\mathrm{hv}=10.8$ $\mathrm{MeV})$. The explanation was that by measuring the carbon to nitrogen ratio one could reduce the number of false alarms due to other objects that had high concentrations of nitrogen by assuring the ratio was consistent with the composition of high explosives. It was also claimed that the nitrogen to silicon ratio was a more sensitive signature for high explosive than the nitrogen alone because of the decrease in silicon gamma-ray flux corresponding to the soil displaced by the mine. The data in Fig. 4 clearly show there is little or no information to be gained by such systems over a system based on simply detecting the presence of nitrogen. 


\section{Summary}

We have modeled the Russian mine-detection technology based on a two phase system that combined information from two separate sensors detecting back scattered neutrons

and the delayed gamma rays resulting from $(\mathrm{n}, \gamma)$ reactions. Our simulations predict results for both phases of detection consistent with the field test results from the 1998 evaluation of the Russian system at BODF. With a $\sim 1.0 \times 10^{7} \mathrm{n} / \mathrm{s}{ }^{252} \mathrm{Cf}$ neutron source the detection of hydrogen associated with $6 \mathrm{~kg}$ of TNT buried a few $\mathrm{cm}$ below the soil is a rapid process taking only a few seconds. But such a system by itself produces numerous false positives. Interrogation of these locations with the second phase would result in a statistically significant $(\mathrm{n}, \gamma)$ signal from nitrogen in $\sim 3$ minutes. Such a system appears to be robust for detecting mines containing $>6 \mathrm{~kg}$ TNT buried to depths $<15 \mathrm{~cm}$.

Another objective of this study was to determine whether or not this particular two-phase methodology could be scaled to detect anti-personnel mines containing a much smaller mass $(\sim 30 \mathrm{~g})$ of high explosive. The data from our simulations indicate a successful scaling to detect buried high-explosives with a mass $<150 \mathrm{~g}$ is simply not practical. Data in Table 1 clearly show the signal-to-background ratio for antipersonnel mines would be so low that there would be many false positives arising from the natural sources of hydrogen concentration in the soil. The data in Fig 4 shows that with $6 \mathrm{~kg}$ TNT, approximately ten $10.8 \mathrm{MeV}$ gamma rays arrive at the detector per 20 million neutrons. Scaling these results by solid angle and mass to a $30-\mathrm{g}$ antipersonnel mine $(4 \mathrm{~cm}$ diameter, $1.25 \mathrm{~cm}$ high) buried at $1 \mathrm{~cm}$ gives a detection rate of 10 gamma rays per 4 billion neutrons. To increase this detection rate to a practical level would require either a significantly stronger neutron source or a geometry that provides a much larger solid angle for the source-mine-detector. The former is ruled out from radiological safety considerations and the latter is limited to gains of $<10$ due to the shielding requirements between the neutron source and the detector. A pulsed neutron source and time gated circuitry offer some attractive possibilities but such considerations are beyond the scope of this study. 


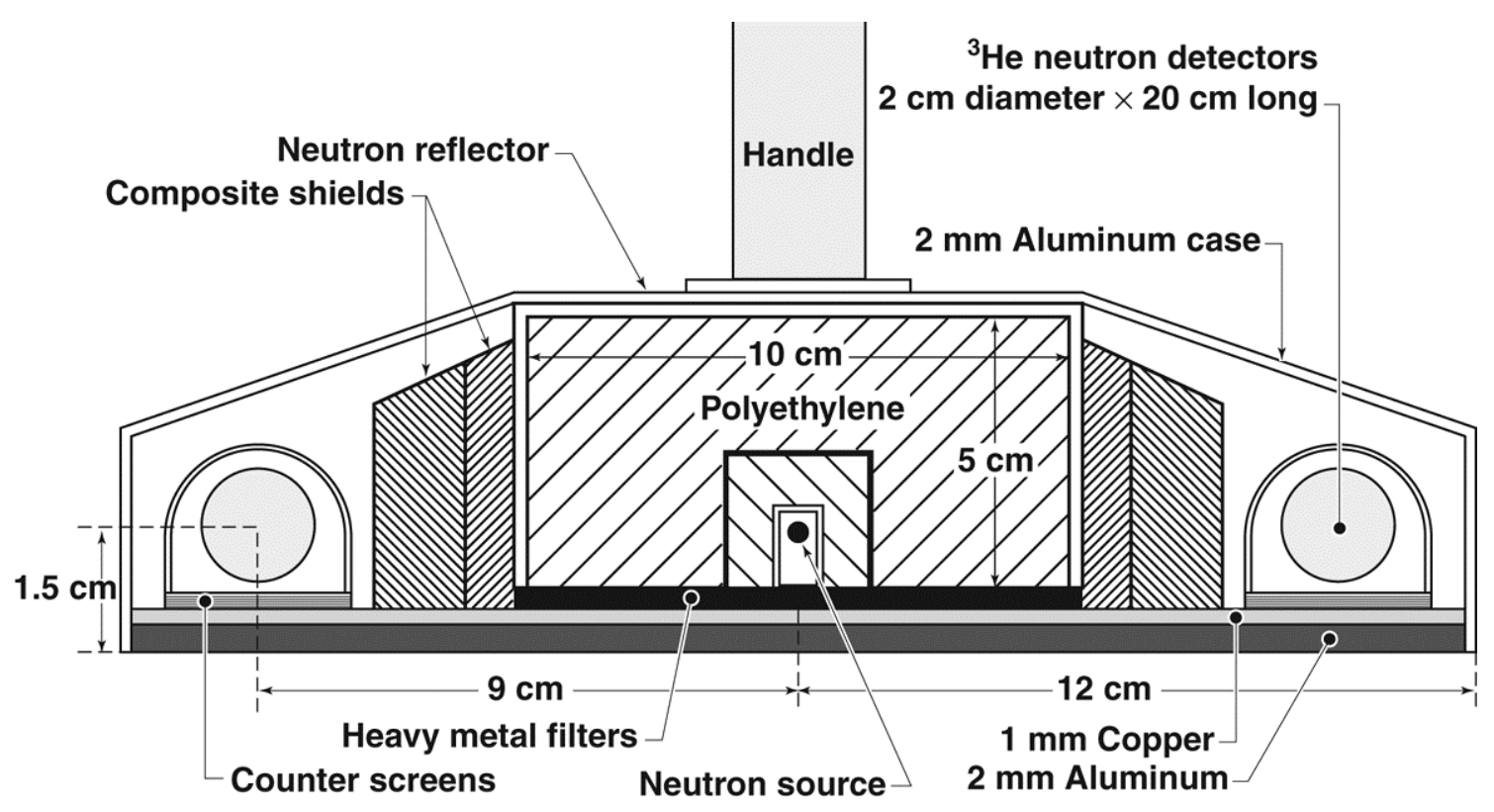

Figure 1

First phase detection system $\left(\mathrm{n}, \mathrm{n}^{\prime}\right) . \mathrm{A}^{252} \mathrm{Cf}$ neutron source $\left(1.2 \times 10^{7} \mathrm{n} / \mathrm{s}\right)$ was mounted in a $5 \mathrm{~cm} \times 10 \mathrm{~cm} \times 10 \mathrm{~cm}$ polyethylene block $1.5 \mathrm{~cm}$ above the base. ${ }^{3} \mathrm{He}$ neutron detectors were mounted on each side of the neutron source at a distance of $9 \mathrm{~cm} .2 .6 \mathrm{~cm}$ thick composite shields were placed between the source and the detectors. 


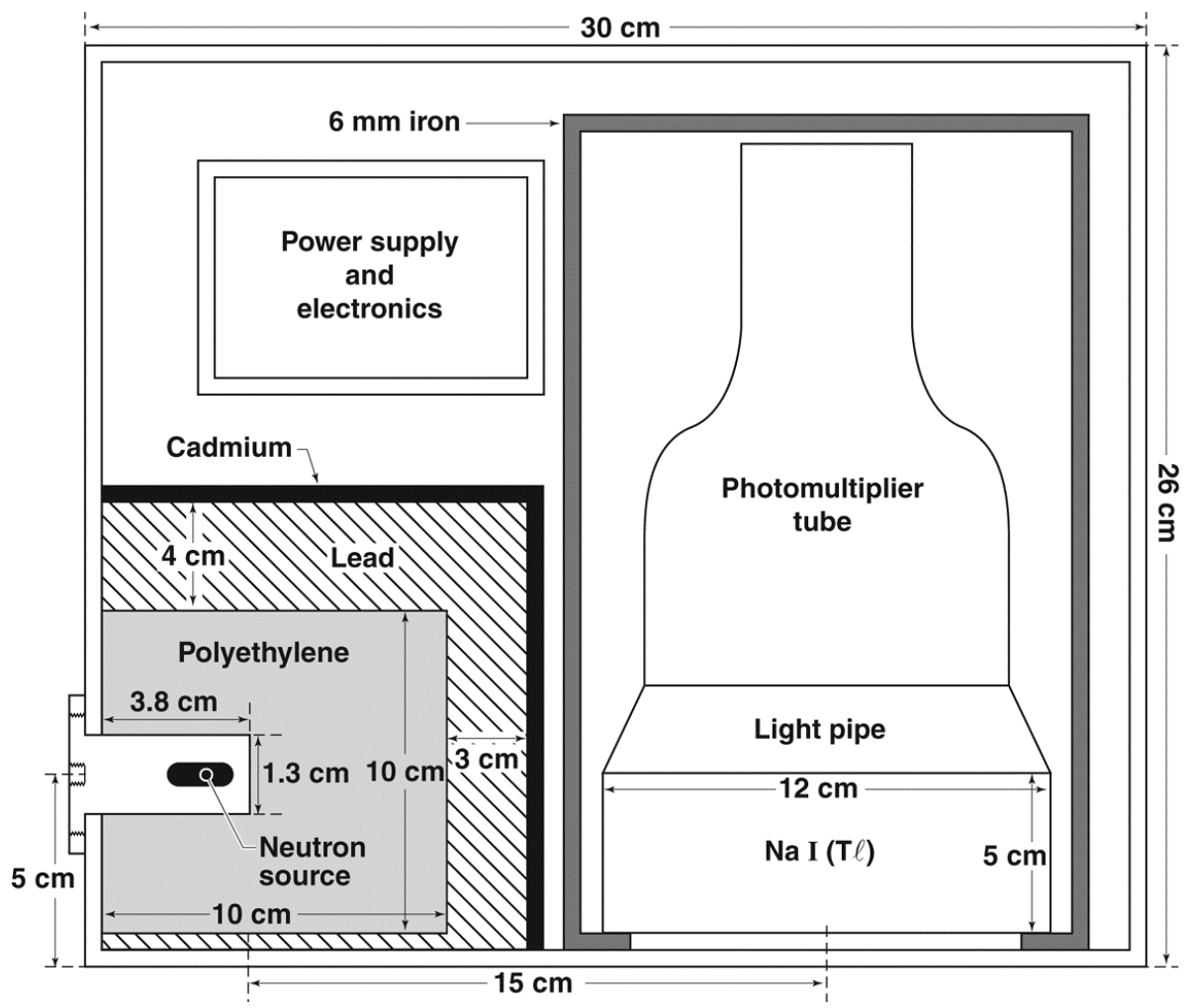

Figure 2

Second phase detection system ${ }^{14} \mathrm{~N}(\mathrm{n}, \gamma)$. $\mathrm{A}^{252} \mathrm{Cf}$ neutron source contained in an aluminum housing $(1.3 \mathrm{~cm}$ diameter by $3.8 \mathrm{~cm}$ long) positioned $5 \mathrm{~cm}$ above the base. The source was mounted in a $10-\mathrm{cm}$ polyethylene cube with a $3-\mathrm{cm}$ thick lead shield between the source and the gamma-ray detector. Top of polyethylene cube shielded with $4 \mathrm{~cm}$ of lead. The outside surface of lead was covered with a 1-mm thick layer of cadmium. A $100-\mu$ m thick gadolinium foil was mounted below the polyethylene cube. The gamma-ray detector was mounted in a 6-mm thick iron cylinder $14-\mathrm{cm}$ diameter, $23-\mathrm{cm}$ long. The wall thickness of the aluminum case is $1 \mathrm{~mm}$. 


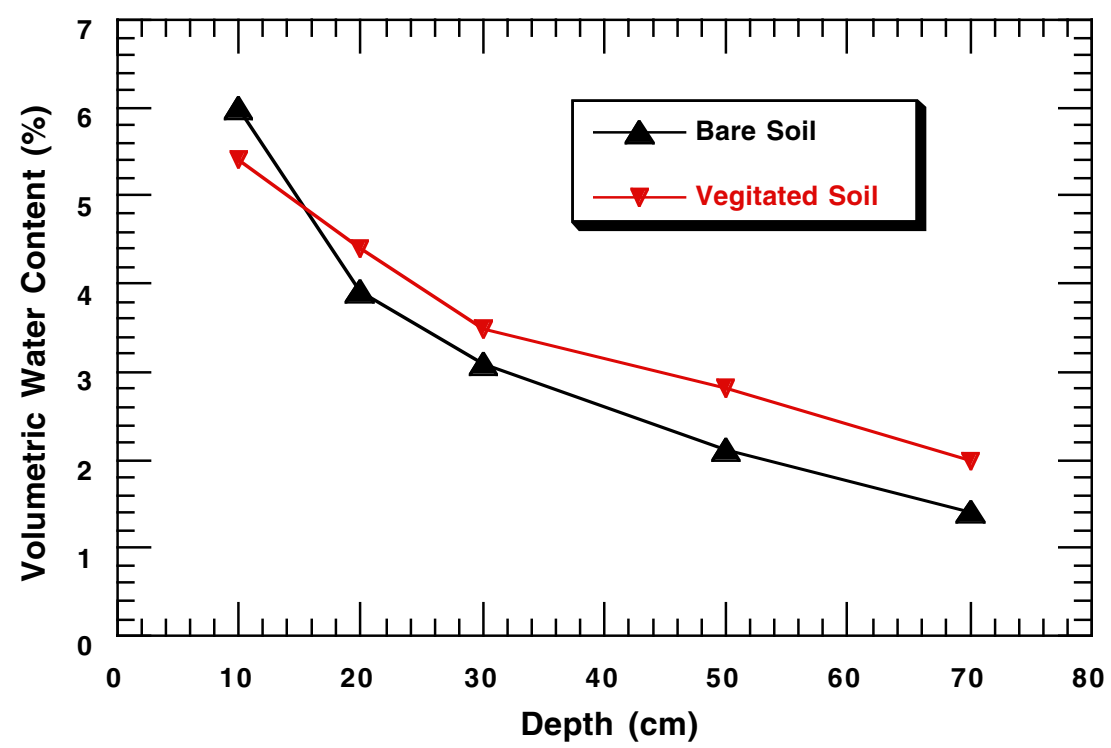

Figure 3 Volumetric water content versus depth. In-situ measurements of the soil moisture were made in the minefield during the mine detection evaluation. The evaluation was conducted during a three day period 6 days after a heavy rain. 

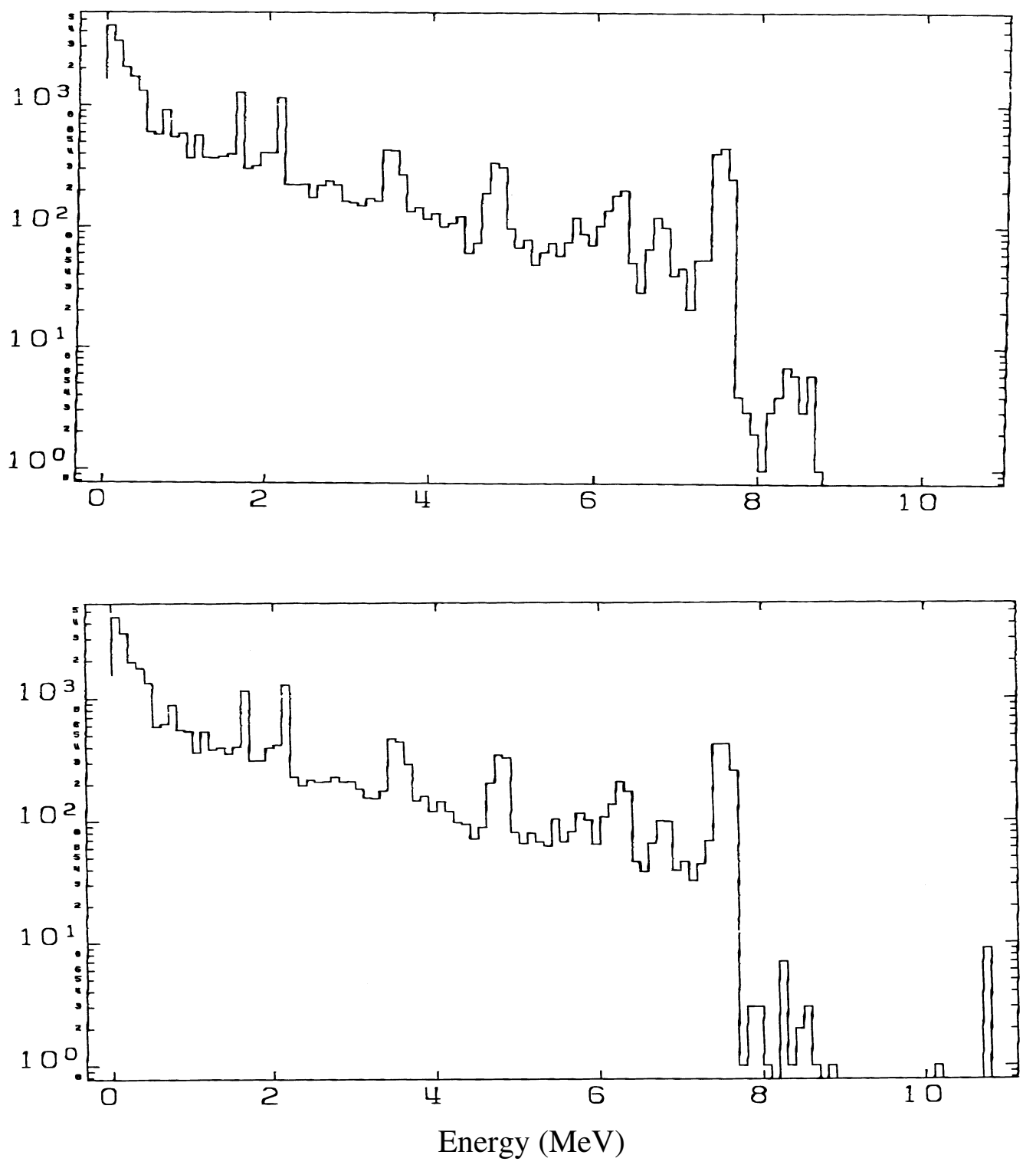

Figure 4

Monte Carlo simulations of $(\mathrm{n}, \gamma)$ spectrum (20 million neutron histories) run during evaluation of Russian-developed technology for the detection of buried mines, showing (a) soil only, and ( b) soil plus $5 \mathrm{~kg}$ of TNT buried $15 \mathrm{~cm}$ below the surface. Note photon peak at $10.8 \mathrm{MeV}$ in (b) shows presence of TNT. 
References:

1. G. Pekarsky, Nuclear Methods and Means for Explosives Detection and Identification, Proc. Intern Conf. On Reactor Physics, Tel-Aviv, 1994, p750

2. H.H.Hsu, K.J. Kearfott, Effects of Neutron Source Selection on Land-Mine Detection Efficiency, Nuclear Instruments \& Methods in Physics research A 422 (1999) 914917

3. T. P. Wilcox, Jr., and E. M. Lent, "COG - A Particle Transport Code Designed to Solve the Boltzmann Equation for Deep-Penetration (Shielding) Problems. Vol. 1: User Manual", LLNL Rept. M-221-1 (1989). Internet COG reference: http://www-phys.llnl.gov/N_Div/COG/

4. "TART95: A Coupled Neutron-Photon Monte Carlo Transport Code", D. Cullen, A. Edwards, E. Plechaty, LLNL Report UCRL-MA-121319, July 4, 1995. Internet Tart reference: http://reddog1.llnl.gov

5. J. F. Briesmeister (Ed.) MCNP - A General Monte Carlo N-Particle Transport code, Los Alamos National Laboratory, LA-12625, 1993

6. W.R. Nelson, H. Hirayama, and D.W.O. Rogers, The EGS4 Code System, SLAC-Report-265, December 1985.

7. Reynolds Electrical \& Engineering Co., Site Characterization and Monitoring Data From Area-5 Pilot Wells, DOE/NV/11432-74 UC721, February, 1994

8. G.P. Lamaze, and J.A. Grundl, "NBS Measurement Services: Activation Foil Irradiation with Californium Fission Sources", Natl. Bur. Stand. (U.S.), Spec. Publ. 250-13, March 1988. 
APENDIX A

MCNP Input Deck for Soil Plus 5 kg TNT

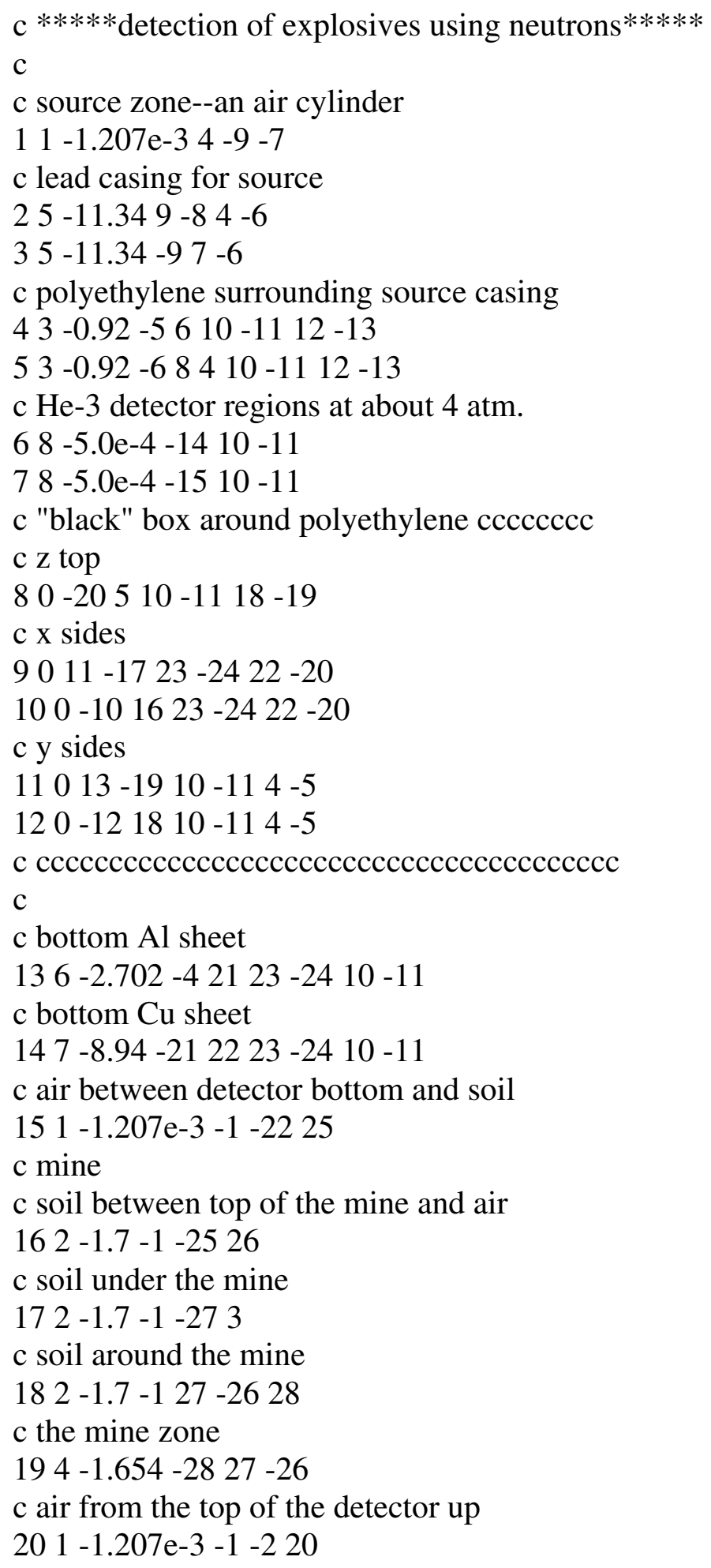


$\mathrm{c}$ air in the $+\mathrm{x}$ sense from the detector

$211-1.207 e-3-122-2017$

$\mathrm{c}$ air in the $-\mathrm{x}$ sense from the detector

$221-1.207 e-3-122-20-16$

$\mathrm{c}$ air in the $+\mathrm{y}$ and $-\mathrm{y}$ sense from the detecor

$231-1.207 \mathrm{e}-3-122-2016-1724$

$241-1.207 \mathrm{e}-3-122-2016-17-23$

c box of air around the cylindrical detectors

251 -1.207e-3 $1410-11 \quad 19$-24 4 -20

$261-1.207 \mathrm{e}-3 \quad 1510-11-18234-20$

$\mathrm{c}$ the rest of the universe

270 1:2:-3

c outermost cylinder

$1 \mathrm{cz} 100$

c top air plane

2 pz 100.0

c soil bottom plane

$3 \mathrm{pz}-50.0$

c source and moderator (borated polyethylene) surfaces

$4 \mathrm{pz}-1.0001$

$5 \mathrm{pz} 4.0$

$6 \mathrm{pz} 1.5$

$7 \mathrm{pz} 1.0$

$8 \mathrm{cz} 1.5$

$9 \mathrm{cz} 1.0$

$10 \mathrm{px}-5.0$

11 px 5.0

12 py -5.0

13 py 5.0

c He-3 detectors cylinders 8-cm off center

$\mathrm{c}$ parallel to $\mathrm{x}$ at each side of the source

$14 \mathrm{c} / \mathrm{x} 8.00 .00 .5$

$15 \mathrm{c} / \mathrm{x}-8.00 .00 .5$

c perfect absorber surfaces around poly box

$16 \mathrm{px}-5.5$

17 px 5.5

18 py -5.5

19 py 5.5

$20 \mathrm{pz} 4.5$

$\mathrm{c}$ bottom of the detector assembly $\mathrm{Al}$ and $\mathrm{Cu}$ sheets

$21 \mathrm{pz}-1.2$

$22 \mathrm{pz}-1.3$

23 py -12.0

24 py 12.0

c soil top plane

$25 \mathrm{pz}-2.5$ 


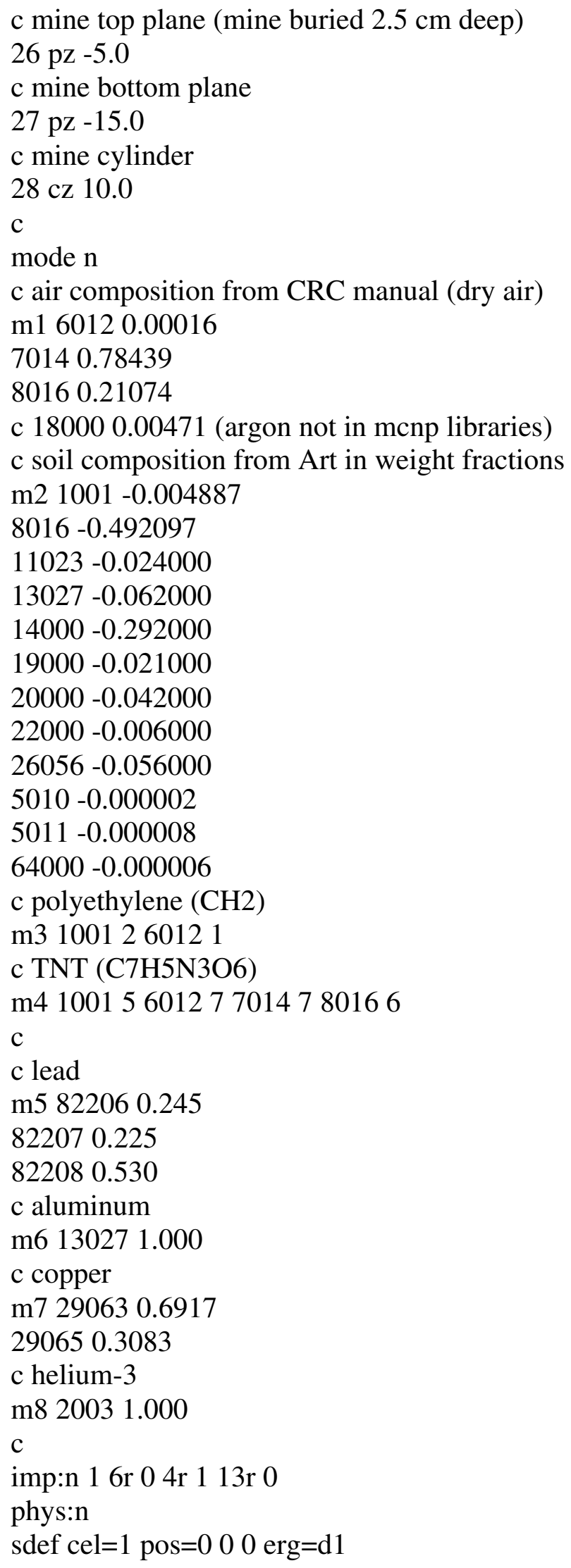




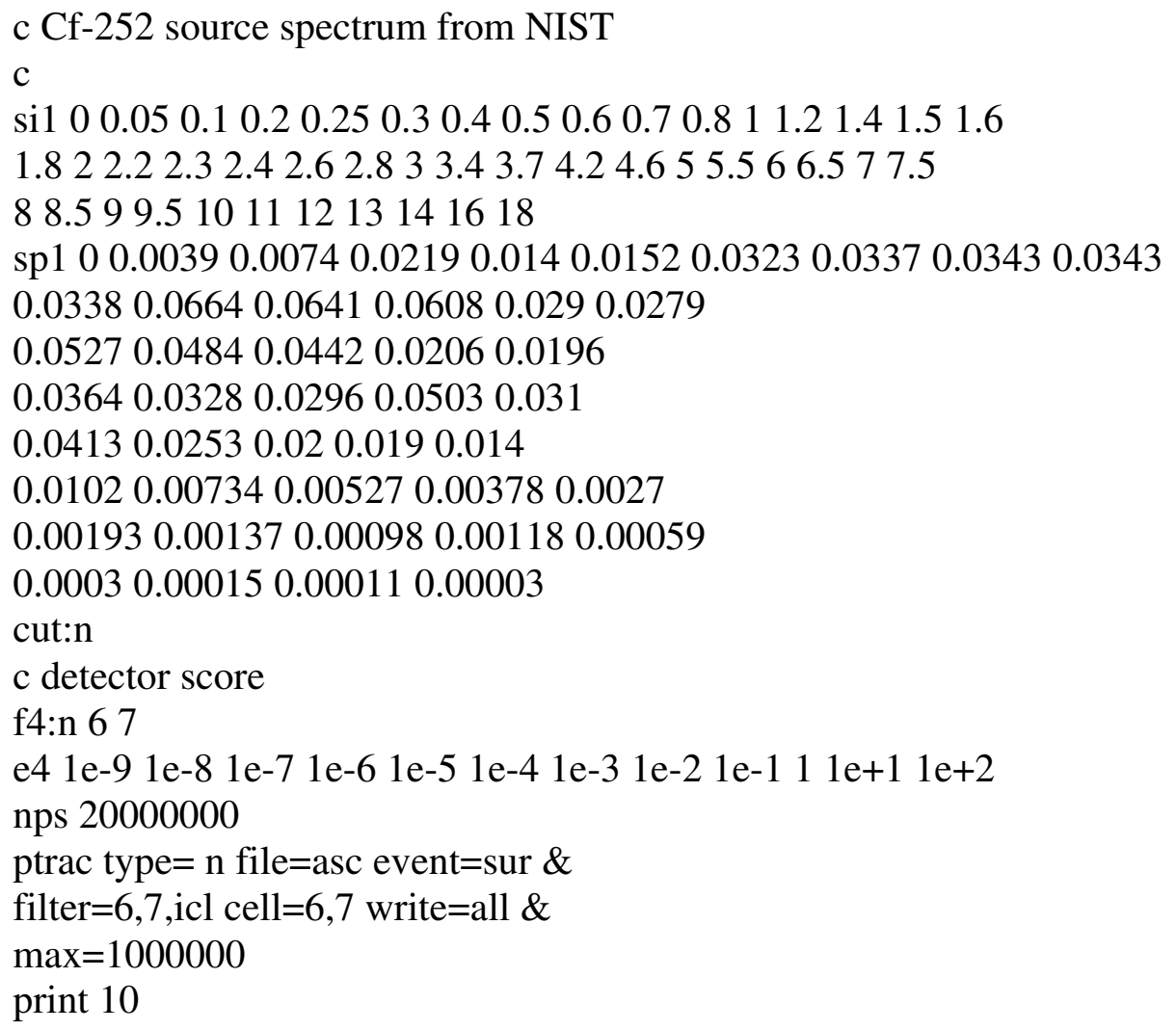


APPENDIX B

MCNP Source Deck for Soil Only

$\mathrm{c} * * * * *$ detection of explosives using neutrons $* * * * *$

$\mathrm{c}$

c source zone--an air cylinder

11 -1.207e-3 4 -9 -7

$\mathrm{c}$ lead casing for source

$25-11.349-84-6$

$35-11.34-97-6$

c polyethylene surrounding source casing

$43-0.92-5610-1112-13$

$53-0.92-68410-11 \quad 12-13$

c He-3 detector regions at about 4 atm.

68 -5.0e-4 -14 $10-11$

$78-5.0 \mathrm{e}-4-1510-11$

c "black" box around polyethylene cccccccc

$\mathrm{c}$ z top

$80-20510-11 \quad 18-19$

c $\mathrm{x}$ sides

$9011-1723-2422-20$

$100-101623-2422-20$

c y sides

$11013-1910-114-5$

$120-121810-114-5$

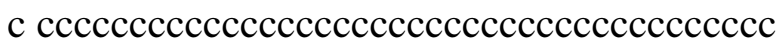

$\mathrm{c}$

c bottom $\mathrm{Al}$ sheet

$136-2.702-42123-2410-11$

c bottom $\mathrm{Cu}$ sheet

$147-8.94-212223-2410-11$

$\mathrm{c}$ air between detector bottom and soil

$151-1.207 \mathrm{e}-3-1-2225$

c mine

c soil between top of the mine and air

$162-1.7-1-2526$

c soil under the mine

$172-1.7-1-273$

c soil around the mine

$182-1.7-127-2628$

$\mathrm{c}$ the mine zone $\& \& \& \&$ TURNED INTO SOIL !!!!!!!

$192-1.7-2827-26$

$\mathrm{c}$ air from the top of the detector up

$201-1.207 e-3-1-220$

$c$ air in the $+x$ sense from the detector 


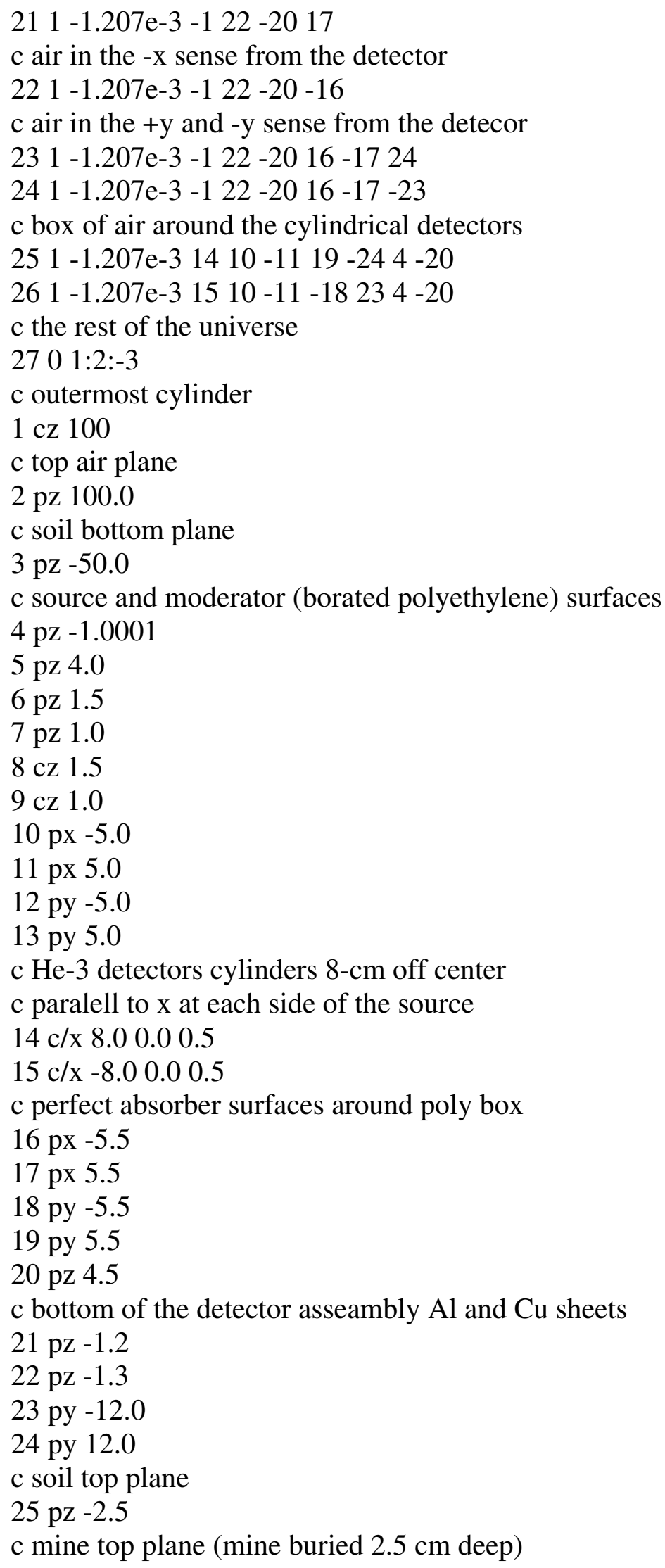




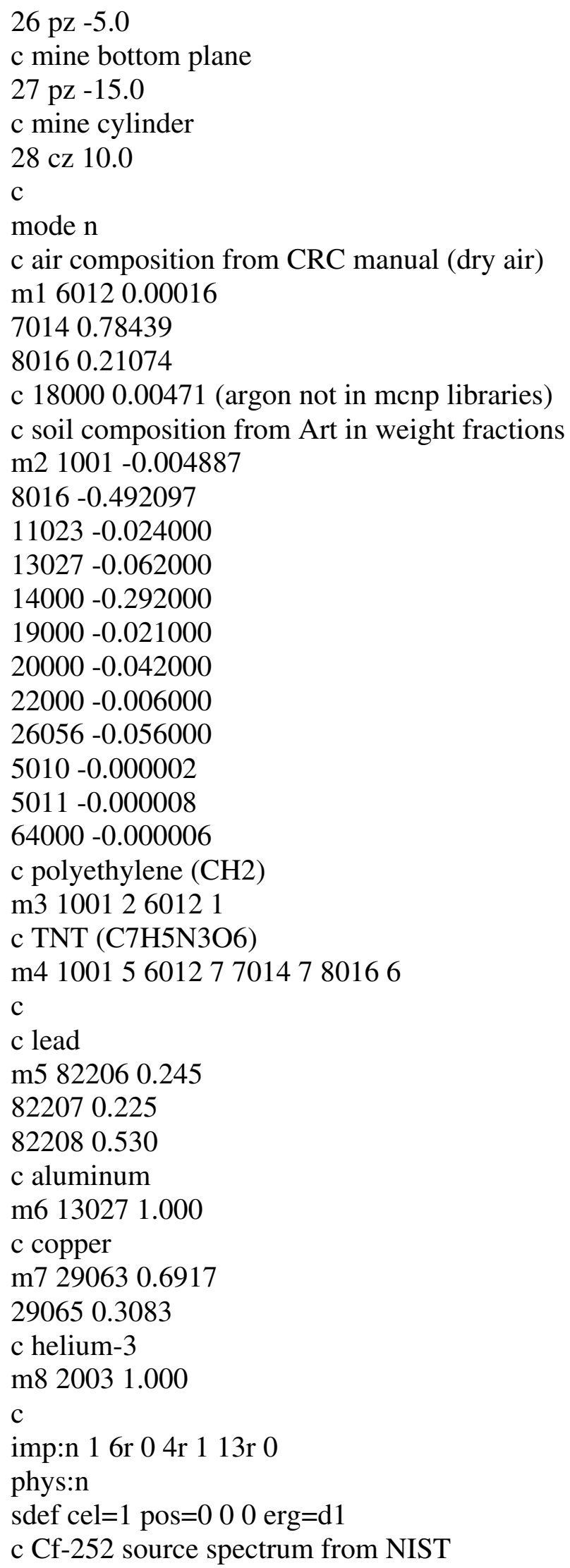




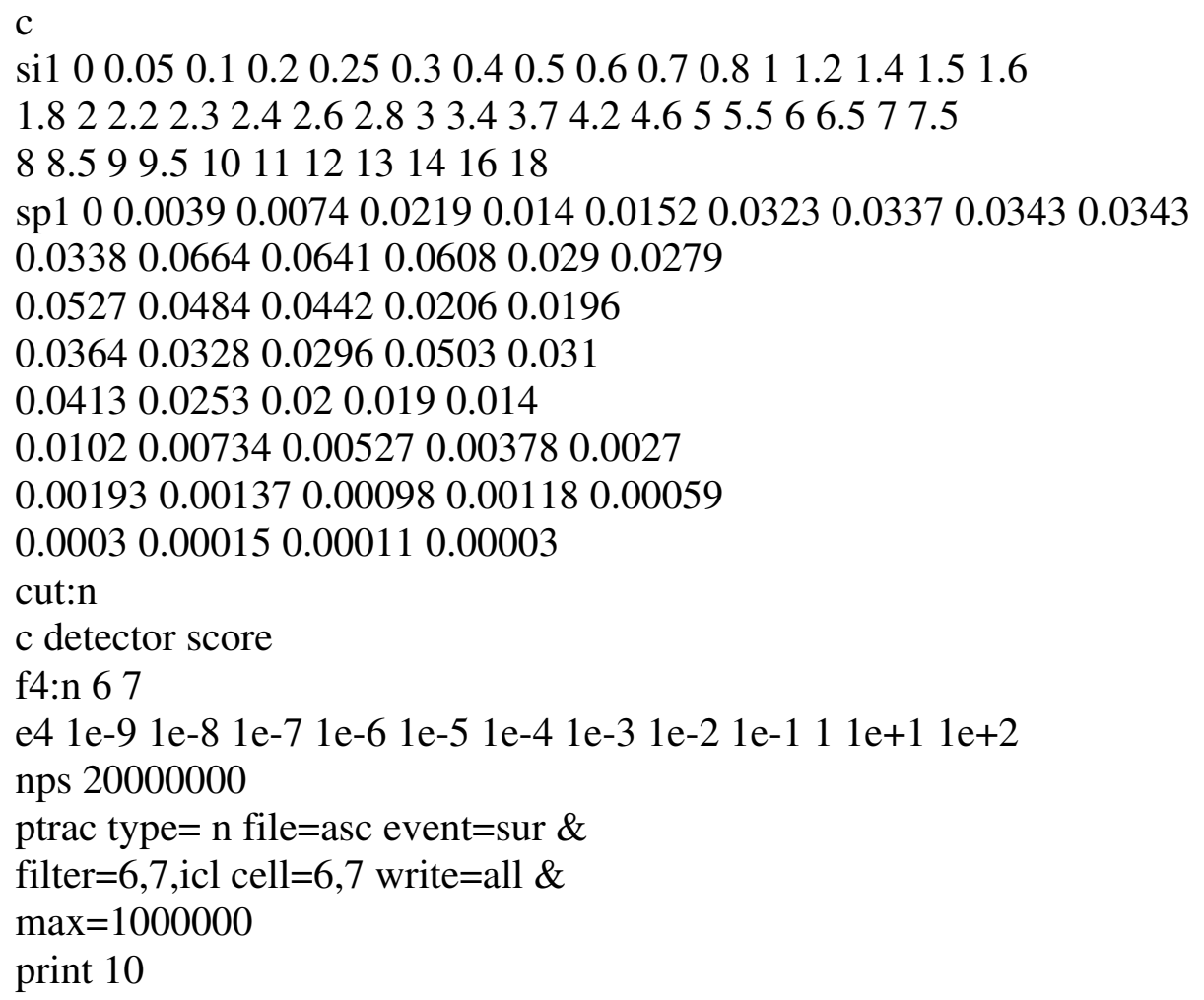

